\title{
O discurso sobre a amizade: diferenças de exposição entre as duas Éticas
}

\author{
Chiara Buffon (Università Cà Foscari)
}

The main aim of this paper is to compare Aristotle's analysis of friendship in Nicomachean Ethics books VIII and IX and in Eudemian Ethics book VII.

Aristóteles dedica à amizade o livro VII da Ética Eudêmia e os livros VIII e IX da Ética Nicomaquéia. Os dois tratados são substancialmente assimiláveis quanto às teses defendidas; todavia, diferenças podem ser encontradas na organização do discurso. Os comentadores discordam sobre o juízo a dar para tais discrepâncias: Fraisse ${ }^{1}$ pensa que a Ética Nicomaquéia está ordenada com maior clareza e distingue nos livros VIII e IX três partes, dedicada uma ao esclarecimento das noções, uma outra à justiça e uma terceira à investigação psicológica; de opinião oposta é Rowe, que considera a argumentação da Ética Eudêmia mais logicamente seqüencial e a Ética Nicomaquéia mais rica de repetições e de argumentos desconectados entre si. $^{2}$

A EE VII pode ser dividida como segue: a primeira parte (1234b18 - 1236a 5) é dedicada a apresentar questões a resolver, endoxa, premissas metodológicas; Aristóteles se ocupa sucessivamente de dar uma definição do que é a amizade, estudando suas diversas propriedades e propriedades (1236a16 - 1241b11); esta parte definicional compreende o estudo dos três fenômenos, benevolência, concórdia e amor de si, que se distinguem da amizade, embora lhe sejam assemelhados. Segue uma seção sobre a justiça (1241b12 1244a37), enquanto a última parte de EE VII (1244b1 - 1246a25) é dedicada ao tratamento

\footnotetext{
${ }^{1}$ pp. $279-286$

2 pp. $52-60$
} 


\section{Journal of Ancient Philosophy Vol. II 2008 Issue 1}

das questões relativas à autarquia e à necessidade de amigos. Pode-se falar, na EE VII, de graus crescentes de contextualidade: primeiramente a amizade é estudada e definida em si, depois são expostas as normas de justiça que ela implica, por fim a amizade é inserida no contexto mais geral da vida feliz.

Em EN VIII - IX, Aristóteles, depois deter introduzido o argumento, realiza uma análise dos três tipos de amizade, a qual é freqüentemente redundante e repetitiva; em particular, a passagem $1157 \mathrm{~b} 6$ - 1158a36 é composta de observações separadas e nas mais das vezes já expressas no mesmo livro. ${ }^{3}$ Dá seguimento a esta passagem uma seção sobre o confronto entre a amizade e a justiça (1158b1 - 1165a36); no interior deste confronto, Aristóteles insere um longo discurso sobre as formas de governo (1159b25 - 1162a33), o qual não tem nenhum correspondente na $E E$.

A parte mais peculiar, porém, do discurso da $E N$ sobre a amizade é o livro IX: ele é composto por uma série de discussões sobre argumentos díspares, o nexo entre eles freqüentemente não sendo evidente. Muitos dos argumentos apresentados estão presentes também na $E E$, mas aqui, na $E N$, estão, por assim dizer, fora de contexto. Por exemplo: o discurso sobre a benevolência e concórdia, que em $E E$ VII serviam de "casos limites" para completar a definição da amizade ${ }^{4}$, estão presentes na $E N$ somente como aprofundamentos marginais e não têm um papel definido na economia do discurso. ${ }^{5}$

A $E E$, em geral, tem uma ordem mais rigorosa com relação à $E N$, mas o que parece mais interessante não é tanto a estrutura em si do discurso quanto a possibilidade de ler em função de motivações mais amplas as diferenças de exposição da $E N$ relativamente à $E E$, em particular as duas mais evidentes, que são as passagens do livro VII sobre as formas de governo, 1159b25 - 1162a33, e a composição de EN IX.

2.

\footnotetext{
${ }^{3}$ Foram dadas várias interpretações a esta passagem (Susemihl-Apelt, pp. 178-181; Susemihl, p. 180 -183; Ramsauer, pp. 520-526; Burnet, p. 371; Gauthier, pp. 681-683; Irwin, p. 124, e pp. 278-279; Pakaluk, pp. 8290; Broadie, p. 411); não se apresentará aqui uma solução ao problema, pois não é essencial para o presente estudo.

${ }^{4}$ Rowe (p. 55) não atribui ao estudo dos philka a mesma função para definir a amizade, mas os inclui, mesmo assim, na primeira seção do discurso, a não ser que estejam em função de acréscimos posteriores.

${ }^{5}$ Pakaluk (pp. 180-181) considera difícil ver qual é a função da passagem sobre a benevolência e concórdia, fazendo a hipótese que aqui Aristóteles teria pretendido acabar com a identificação platônica entre concórdia, amizade e harmonia interior. Gauthier (p. 725) identifica aqui com correção uma polêmica antiplatônica.
} 
Na EN VIII 1159b25 - 1162a33, Aristóteles ilustra os três tipos de constituição e as formas degeneradas correspondentes. O discurso está inserido no estudo da relação entre amizade e justiça. Inicialmente Aristóteles afirma que amizade e justiça ocorrem entre as mesmas pessoas, estabelecendo-lhes a co-extensividade. ${ }^{6}$ Em seguida, depois de ter dito que existem diversas formas de justiça e que todas as comunidades são partes da comunidade política, Aristóteles se delonga em uma análise das formas de governo (1160a31 - 1160b21); somente em um segundo momento ele põe em relação esta análise com as relações privadas de amizade que constituem o tema do livro.

É interessante o fato que o estudo das constituições na $E N$ tem uma certa autonomia relativamente ao contexto: as formas de governo são analisadas por si mesmas antes de serem postas em conexão com a amizade. ${ }^{7}$ Isso não ocorre na $E E$; com efeito, em $1241 \mathrm{~b} 27$ - 33, de modo muito mais conciso, as formas de governo são mencionadas somente por causa de sua relação com os elos de amizade entre familiares, a saber, com o objeto principal do tratado, mas não são estudadas em si e por si.

Em ambos os discursos sobre a amizade faltam outras digressões de matéria política que expliquem mais claramente a razão do maior interesse que o tema das constituições ganha na $E N$. Um sinal que pode nos fornecer uma chave interpretativa pode ser encontrado em duas afirmações que se encontram no início de cada um dos discursos. Seja no início de $E N$ VIII, seja no primeiro capítulo de $E E$ VII, é indicado um nexo entre amizade e política. $\mathrm{Na} E N$ Aristóteles afirma:

"ao que parece é a amizade que mantém a cidade unida" (1155a23 - 24),

ao passo que na $E E$ sustenta que:

"se opina, de fato, que a maior tarefa da política consista em estabelecer a amizade" $(1234 b 21-22)$.

Ora, é preciso notar como a relação de dependência aparece aqui invertido: na $E E$ é a política que funda a amizade, na $E N$ é a amizade que funda a política. A partir disso, talvez, se pode explicar a importância que recebem as formas de governo: se a amizade é o

\footnotetext{
${ }^{6}$ Cfr. Pakaluk 111.

${ }^{7}$ Ramsauer (p. 548) sustenta, ao contrário, que Aristóteles observa sobre as constituições somente o que é útil para a ética; na verdade, do confronto com a $E E$ pode-se ver como o lugar o da digressão é de não pouca importância quanto a extensão e autonomia.
} 


\section{Journal of Ancient Philosophy Vol. II 2008 Issue 1}

que une a cidade e é o fundamento da política ${ }^{8}$, então as constituições estão baseadas no mesmo elo que une entre si os amigos ou os familiares. A associação entre pai e rei em $E N$ VIII, por exemplo, não é usada por Aristóteles como uma mera metáfora para explicar a relação do pai com os filhos, mas Aristóteles quer sustentar que é justamente a relação de philia a ser a mesma. Estudar as constituições, portanto, equivale a estudar as formas de amizade $^{9}$, o que pode justificar a inserção da digressão.

Para compreender, pois, por que o interesse pela política é mais vívido na $E N$, deve-se voltar ao início da obra: já em 1094b 12 Aristóteles define a sua investigação "em certo sentido política". Ademais, na EN é recorrente, de modo significativo, a definição do homem como animal político $(1097 \mathrm{~b} 11,1169 \mathrm{~b} 18,1162$ a 18), a qual, por sua vez, tem uma só ocorrência na $E E$, e ainda de modo a relativizar sua importância:

“o homem é um animal não somente político, mas também doméstico" (1242a23).

Pode-se, portanto, constatar que, quanto ao tange ao interesse pela política, os livros sobre a amizade presentes na $E N$ parecem ser solidários com o clima geral da obra.

3.

Como se disse acima, uma das diferenças principais entre os dois discursos sobre a amizade é que, na $E E$, não há nenhuma parte que corresponda ao conteúdo de $E N$ IX. Disso se pode tirar observações gerais sobre os propósitos da obra.

$E N$ IX contém, nos dois primeiros capítulos ${ }^{10}$, o término da casuística relativa à justiça e às querelas. No resto, o livro trata, na ordem: a amizade a quem não permanece o mesmo; o amor de si; a benevolência; a concórdia; as relações entre beneficentes e beneficiados; os dois tipos de egoísmo; se o homem feliz precisa de amigos; o número de amigos que é melhor ter; a amizade na boa e na má sorte. Segue uma conclusão na qual Aristóteles reafirma que a amizade é comunidade.

Destes argumentos, três não têm correspondentes na $E E$, a saber: os dois tipos de egoísmo, se devemos manter a amizade em relação a quem não permanece o mesmo, o

\footnotetext{
${ }^{8}$ Gauthier (p. 702) oferece uma interpretação meramente genealógica: o Estado deriva da família e herda dela a estrutura. Mesmo que esta interpretação não seja implausível, não me parece apta a explicar as diferenças entre as constituições. Tricot (p. 411) inverte (ou não nota) esta relação de dependência e afirma que conhecer as politeiai significa conhecer as philiai que derivam dela; porém, nada diz sobre 1155a 23-24.

${ }^{9}$ Para Gauthier (p. 697) são formas de amizade útil, a qual, contudo, pode elevar-se a uma concepção mais alta de comunidade.

${ }^{10} 1163 \mathrm{~b} 28$ - 1165a 36.
} 


\section{Journal of Ancient Philosophy Vol. II 2008 Issue 1}

número de amigos que se deve ter. A este último tema se faz aceno, en passant, em EE (1245b20 -25), mas no contexto de um outro discurso e muito sumariamente.

O primeiro argumento, a distinção dos dois tipos de egoísmo, é uma retomada, em outros termos, do tema do amor de si, enquanto os dois outros argumentos se apresentam como recomendações práticas.

Quanto ao segundo argumento - a amizade em relação a quem não permanece o mesmo, ele é discorrido em EN IX 3 (1165a36 - 1165b37). Aristóteles parte de uma aporia que concerne a um problema prático: como comportar-se com um amigo que mudou radicalmente? Será preciso desfazer de súbito a amizade? Será preciso tratar o ex-amigo com particular frieza? Como se vê, Aristóteles se pergunta duas questões muito concretas.

No terceiro argumento, discorrido em 1170b20 - 1171a20, Aristóteles se ocupa de quantos amigos é mais vantajoso possuir e segundo que condições. O capítulo inicia com uma pergunta, que em seu interior contém um referimento às opiniões correntes, e se conclui com um ensinamento prático, sobre o número de amigos mais vantajoso nos vários tipos de relação:

"Nas relações políticas é possível ser amigo de muitos sem ser subserviente e permanecendo pessoa de fato boa, mas não é possível ser amigo de muitos pela virtude por eles próprios e devemos nos contentar se há amigos deste tipo, ainda que poucos" (1170b20 1171a20).

A forma na qual este argumento é discutido é particularmente interessante, pois muitos capítulos da EN IX têm uma forma similar: abrem-se com uma pergunta, ou cm um problema ou com endoxa, e se concluem com uma máxima introduzida por um dei , por um adjetivo verbal ou por uma outra expressão indicando dever (1164b20: dei ; 1165a36: dioristeon; 1166b27 - 28: f eukt eon, peirat eon; 1169b2: dei, ouj crhy 1170b18: dei; 1171a20: aggaphton; 1171b27 - 28: euj abht eon, a if et hy. Tais expressões sublinham a transmissão de um preceito moral prático, ensinamento em vista do qual cada problema é analisado.

O capítulo IX 3 (1165a36 - 1165b37), já citado, comporta-se do mesmo modo, mas com uma forma expositiva particular. Aparentemente, com efeito, neste capítulo as questões aristotélicas ficam sem resposta e, em conclusão, não há o habitual ensinamento prático. Porém, olhando melhor, o leitor é igualmente levado a tirar uma conclusão operativa, ainda que não de modo explícito. Aristóteles, com efeito, opõe duas soluções e, 


\section{Journal of Ancient Philosophy Vol. II 2008 Issue 1}

primeiramente, propõe uma das duas possibilidades sob a forma de pergunta e de modo muito conciso; depois, sempre em forma interrogativa, apresenta a oura possibilidade, desta vez inserindo argumentos em seu apoio. Portanto não permanecem dúvidas sobre qual das duas opções ele considera a melhor. Que a resposta ao problema prático seja somente aparentemente eludida é demonstrado por 1165 b21 - 26. Aristóteles apenas se pôs a questão $(1165 b 17$ - 21) se a amizade em relação a quem se torna mau deve ser parada de súbito ou se devemos tentar redimir o amigo, que a segunda possibilidade é definida por ele, no interior da própria pergunta, como uma atitude

"melhor e mais apropriada em uma relação de amizade (...)" (1165b2).

Aristóteles, portanto, embora justifique o primeiro comportamento como "compreensível", deixa ver claramente que julga o outro mais virtuoso. Somente os capítulos 5 a 7 são exceção a esta posição geral prática, visto que tratam de argumentos marginais (concórdia, benevolência, beneficentes e beneficiados) que não implicam uma exortação prática particular. Porém, nos capítulos que seguem reencontramos de novo, com algumas variações, o modelo acima descrito.

Em conclusão, podemos dizer que Aristóteles, na EN IX, leva em consideração uma série de questões de interesse mais prático do que especulativo e que o seu modo de apresentar os argumentos é didático, funcional para a transmissão de um preceito de vida: o que vai ao encontro do interesse prático mais acentuado da $E N$ em relação à $E E$.

4.

À conclusão de uma maior atenção à prática por parte da EN VIII - IX conduz também um traço estilístico, a saber, a maior retoricidade desta obra em relação à $E E$. J[a se viu no parágrafo precedente como Aristóteles usa estruturas argumentativas e expositivas particulares para transmitir sua mensagem. A isto é preciso acrescentar outros expedientes destinados a persuadir o leitor, os quais não têm correspondentes na $E E$ VII.

A EE VII 1 inicia com uma lista de problemas teóricos sobre a natureza da amizade (1234b18 - 21), à qual dá seguimento uma ampla lista de endoxa. Ao contrário, EN VIII 1 inicia focando imediatamente a atenção no valor da amizade. Para exaltá-la, Aristóteles antecipa de pronto uma das conclusões a que chegará nos últimos parágrafos, a saber: a necessidade de ter amigos quando já se possui todos os outros bens (1155a3 sg.). A isto acrescenta um conjunto de circunstâncias diversas ou opostas entre si (riqueza e pobreza, 


\section{Journal of Ancient Philosophy Vol. II 2008 Issue 1}

juventude e velhice etc.) para mostrar como a amizade é um bem em todos os casos (1155a6 -23). Vê-se bem, portanto, como na $E E$ a atenção está voltada a preparar a análise dos conceitos de que se ocupará o livro, enquanto na $E N$ o que interessa é demonstrar imediatamente ao leitor que a amizade é um valor importante e algo útil.

Tanto na $E E$ quanto na $E N$ a condição dos perversos é descrita como dominada pela discórdia: Aristóteles, em particular, se põe a descrever tais condições falando da amizade por si mesmo. Porém, a passagem da EE (1240b11 sg.) preocupa-se sobretudo em reafirmar a inconstância do ânimo do perverso; Aristóteles subdivide os vários aspectos da tal instabilidade (akrates, metameletikos, pseustes) em função de sua ação no tempo e os contrapõe ao estado diverso do homem agathos.

Na EN 1166b6 - 29, Aristóteles faz um impressionante desenho da condição do perverso. No lugar de fazer uma contraposição ponto por ponto segundo os vários aspectos, em EN IX 4 Aristóteles primeiramente expõe o estado de concórdia do homem bom e depois passa a ilustrar as penas do perverso. A passagem 1166b6 - 13 é um crescendo de conseqüências negativas: Aristóteles explica que os perversos escolhem prazeres danosos, se abstêm por vileza de ações que aprovam, por fim são tão odiados que chegam a matar-se. Ilustrada a infelicidade das escolhas dos perversos, o autor aumenta a dose descrevendo a miséria de seu estado interior: os perversos, nos diz Aristóteles, tentam evitar a própria companhia, não têm afeição por si mesmos, ficam agitados por contrastes de tensões dilacerantes (literalmente: w\$per di a s p wǹt a , 1166b20-21); se entristecem logo dos prazeres que provam e são repletos de remorso.

Também na $E E$ Aristóteles afirmava que os perversos são inimigos de si mesmos (1240b14), mas na $E N$ põe diretamente sob os olhos do leitor o tormento deles de modo muito persuasivo (ou melhor, dissuasivo).

A conclusão, com a qual o leitor não pode senão convir, é a seguinte: "se deve, portanto, evitar com toda atenção a perversidade e esforçar-se em ser pessoa de bem" (1166b26-27).

5.

Pode-se, portanto, concluir confirmando a presença de um maior interesse prático na $E N$ na base de pelo menos dois elementos: a presença mais nutrida de questões particulares ligadas à prática, com as respectivas soluções, e não um desenvolvimento 


\section{Journal of Ancient Philosophy Vol. II 2008 Issue 1}

sistemático dos conceitos; o uso de um estilo adaptado a impressionar o leitor e mais ajustado a persuadi-lo. Podemos talvez fazer a hipótese que a $E N$ foi escrita com vistas a uma difusão mais vasta, ao passo que a $E E$ ficou mais ligada ao ambiente da escola e de suas discussões.

Poder-se-ia também sustentar que tanto a presença do elemento político como a maior atenção prática da seção sobre a amizade na $E N$ respondem à intenção geral da ópera; de fato, na EN I 1-3 Aristóteles afirmou que a sua investigação é em certo modo política e

que o seu fim é prático; encontramos reflexos de ambos os propósitos nos livros sobre a amizade. Talvez seja discutível que isto basta para demonstrar que pertencem originariamente à obra, mas seguramente, como mostrado, testemunha um acordo com as linhas gerais da $E N$.

Referências Bibliográficas

Broadie, S. Ethics with Aristotle, Oxford 1991.

Fraisse, J. C. Philia. La notion d'amitié dans la philosophie antique, Paris 1974.

Gauthier, R.-A. e Jolif, J. Y. L'Ethique à Nicomaque, intr. trad. e com., Paris-Louvain 1959, 1970².

Natali, C. Etica Nicomachea, trad. introd. e notas, Roma-Bari 1999, $2001^{3}$.

Pakaluk, M. Aristotle. Nicomachean Ethics books VIII and IX, transl. and comm., Oxford 1998.

Ramsauer, G. (ed.) Aristotelis Ethica Nicomachea, Leipzig 1878.

Rowe, Ch. The Eudemian and Nicomachean Ethics. A study in the development of Aristotle's thought, Cambridge 1971.

Susemihl, F. e Apelt, O. (eds.), Aristotelis Etica Nicomachea, Leipzig 1903.

Tricot, J. Ethique à Nicomaque, Paris 1987.

[Traduzido por Marco Zingano e revisto por Barbara Botter] 